\title{
Embedded Fuzzy Based Boiler Control
}

\author{
Celin S, Anne Frank Joe, Rajalakshmi G, Thaj Mary Delsy T, Jamuna Rani D \\ Assistant Professor, Sathyabama University, India
}

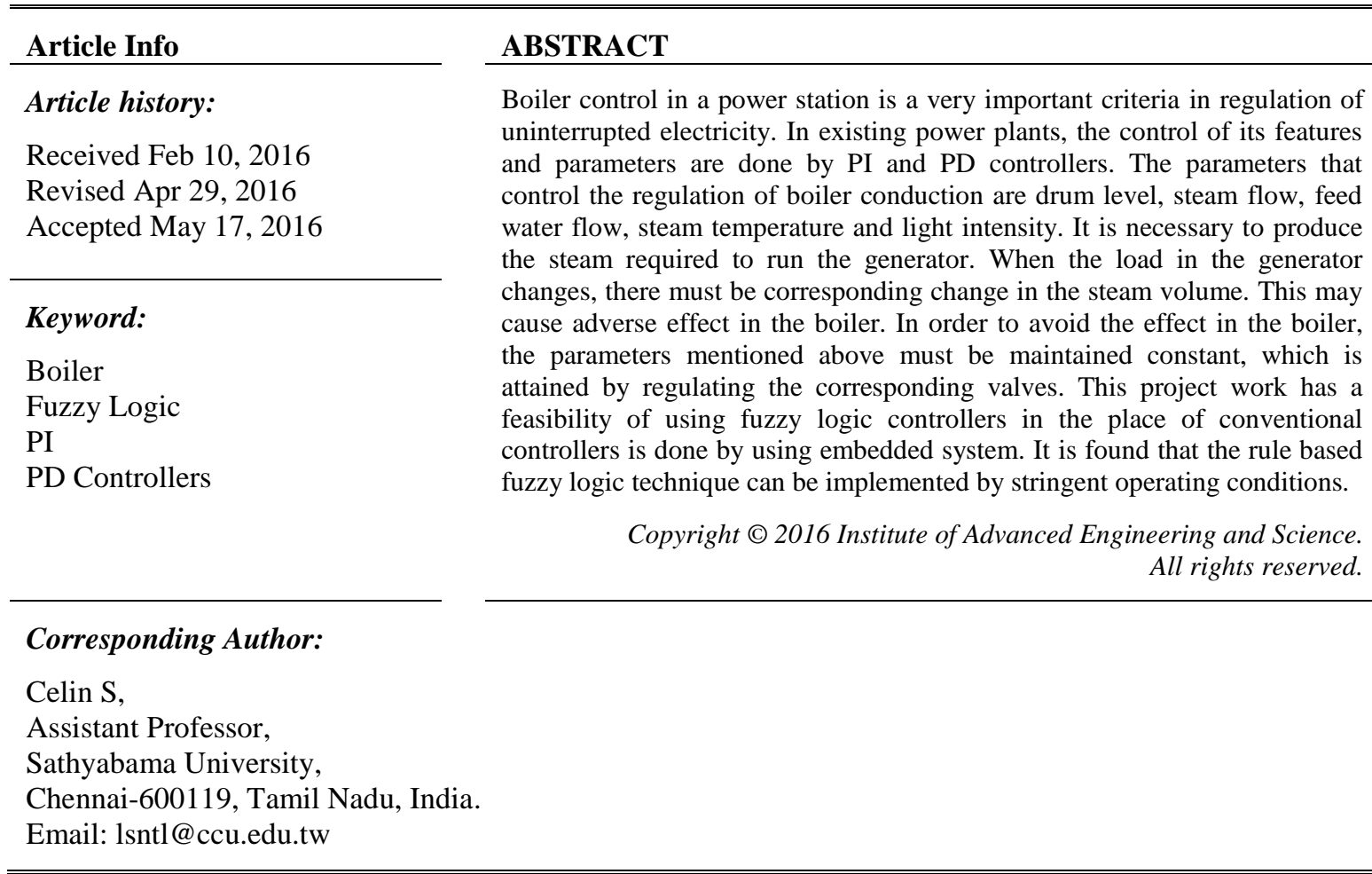

\section{INTRODUCTION}

The power plant considered in this project is pulverized coal firing steam boiler generation unit rated at $200 \mathrm{MW}$. The maximum steam consumption of the power plant is $670 \mathrm{~T} / \mathrm{h}$ at a superheated steam, pressure, temperature of $16.7 \mathrm{MPa}$ and 540 degree Celsius respectively. A two stage water sprayer is used to control the superheated steam temperature by controlling the flow of spray water.

The steam generated from the boiler drum passes through the low temperature super-heated before it enters the radiant type platen super heater. Water is sprayed over the steam to control the superheated steam temperature in both super heaters. There must beproper control of the superheated steam temperature is to ensure the overall efficiency and safety of the power plant. If the temperature of the steam is too high, it can damage the super heater and high pressure turbine, or if it is too low as it will lower the efficiency of the power plant. Therefore, the superheated steam temperature will be controlled by adjusting the flow of spray water to within $\pm 10^{\circ} \mathrm{C}$ during the transient states, and $\pm 5^{\circ} \mathrm{C}$ at the steady state. To prolong the life of the unit, the temperature fluctuations inside the super heater must be reduced.The reduction of these fluctuationshelps in minimizing the stress that causes the micro cracks in theunit. As the embedded fuzzy logic based boiler control is derived to minimize these fluctuations, it is one of the controllers that are most suitable for achieving this goal.

In thermal power plants, the steam used is produced by 'water-tube' boilers, where the walls of the combustion chamber are lined with tubes through which water is passed. In these boilers, fuel is mixed with the correct amount of air and burned in a combustion chamber. The volume of air and amount of fuel that is burnt must be in correct proportion and must not be surplus or deficit. This ratio which is called as the stoichiometric air or fuel ratio is supporting the process. A general diagram of a boiler system is shown below in Figure 1. 


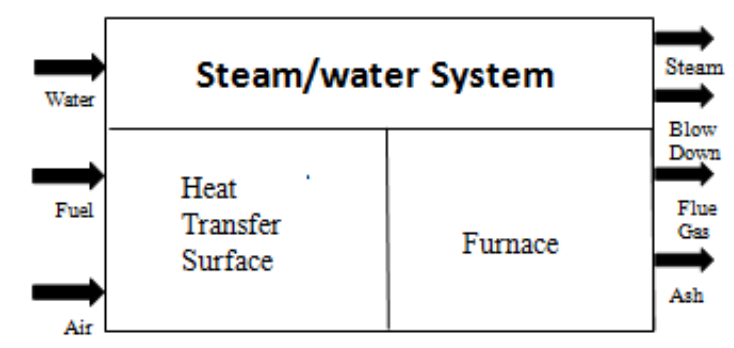

Figure 1. General Outline of Boiler System

The heat released by burning the fuel is used to evaporate water in the boiler. Here the steam is separated from the water in a drum. The steam collecting at the top of the drum is passed to banks of tubes (super heater) in the combustion chamber, where additional heat is added to it, 'super heating' the steam and it is passed to one stage of the turbine, the high pressure (H.P) stage and then return to the boiler for reheating before being used in the turbine again, in this way gaining maximum benefit from the medium. On emerging from the reheating chamber, the steam enters the intermediate pressure (I.P) stage and finally the low pressure (L.P) stage of the turbine, which drives the electrical generator.

After the turbine has extracted most of the heat energy from the steam, the vapor is passed to a condenser, where a heat exchange with circulating cooling water returns the fluid to its liquid phase. In order to obtain more work from the steam passing through the turbine, the condenser operates at vaccum conditions, the magnitude of which is determined by the temperature of the cooling water and the efficiency of the condenser. The condensate is removed by extraction pumps and eventually returned to the boiler feed system via feed heaters.

Before the water is put into the boiler, entrained or dissolved gases such as carbon-dioxide will pass into the steam and turn into corrosive carbonic acid in the heat exchangers that use the steam. This corrodes the heat exchangers and the condensate return piping system. At temperature of boiler water, oxygen, if allowed to reach the boiler, can seriously corrode the boiler. Any remainder that leaves the boiler with the steam can corrode the heat exchangers and return lines. Eliminating these entrained or dissolved gases before they can enter the boiler is called deaeration and is done by a deaerating heater.

\section{PARAMETERS TO BE CONTROLLED IN A BOILER}

The drum boiler system is the steam generation unit within most fossil fuelled power plants. Water is fed into the drum. This water is constantly circulated into the down comers, which are large diameter tube, and back up the risers through the furnace where they are supplied with heat and are boiled. The risers are large number of small diameter tubes to maximize heat exchange. The mixture of water and steam from the risers re-enters the drum. Here they are separated and the steam is released to spin the turbine and thereby generate the electricity. below.

There are a number of parameters that are to be controlled in thermal power plant. They are mentioned

1. Steam temperature of the boiler

2. Maintenance of pressure during the process

3. Maintenance of drum level in the boiler drum

4. Fuel quality

There are various control methods to maintain these parameters in the power plant. The methods used are older methods and they do lag in accuracy. Hence to provide accuracy in outputs various other modern techniques were invented. In this paper the control of steam temperature is alone illustrated.

\section{TRADITIONAL METHOD}

Continuous processes in power plant and power station [Fig(2)] are complex systems characterized by nonlinearity, uncertainty and load disturbance. The super heater is amain part in the process of generation of steam in the boiler and turbine system, where steam is heated to its superheat temperature before entering the turbine, which in turn drives the generator. Due to the deviations in the temperature and pressure in the boiler, the steam generated is extremely nonlinear. Therefore, controlling superheated steam temperature is not only technically challenging but also economically important. 
The steam generated from the boiler drum passes through the low temperature super heater before it enters the radiant type platen super heater. Water is sprayed onto the steam to control the superheated steam temperature in both low and high temperature super heaters. Proper control of the superheated steam temperature is extremely important to ensure the overall efficiency and safety of the power plant. If the steam temperature is too high, it can damage the super heater and the high pressure turbine, or if it will be too low, it will lower the efficiency of the power plant. Hence it is also very important to reduce the temperature fluctuations inside the super heater, as it can help minimize the mechanical stress that causes micro-cracks in the working unit, henceforth to prolong the life of the unit and to reduce the maintenance costs. The existing GPC is developed by reducing these fluctuations, because of which it is considered as a successful controller.

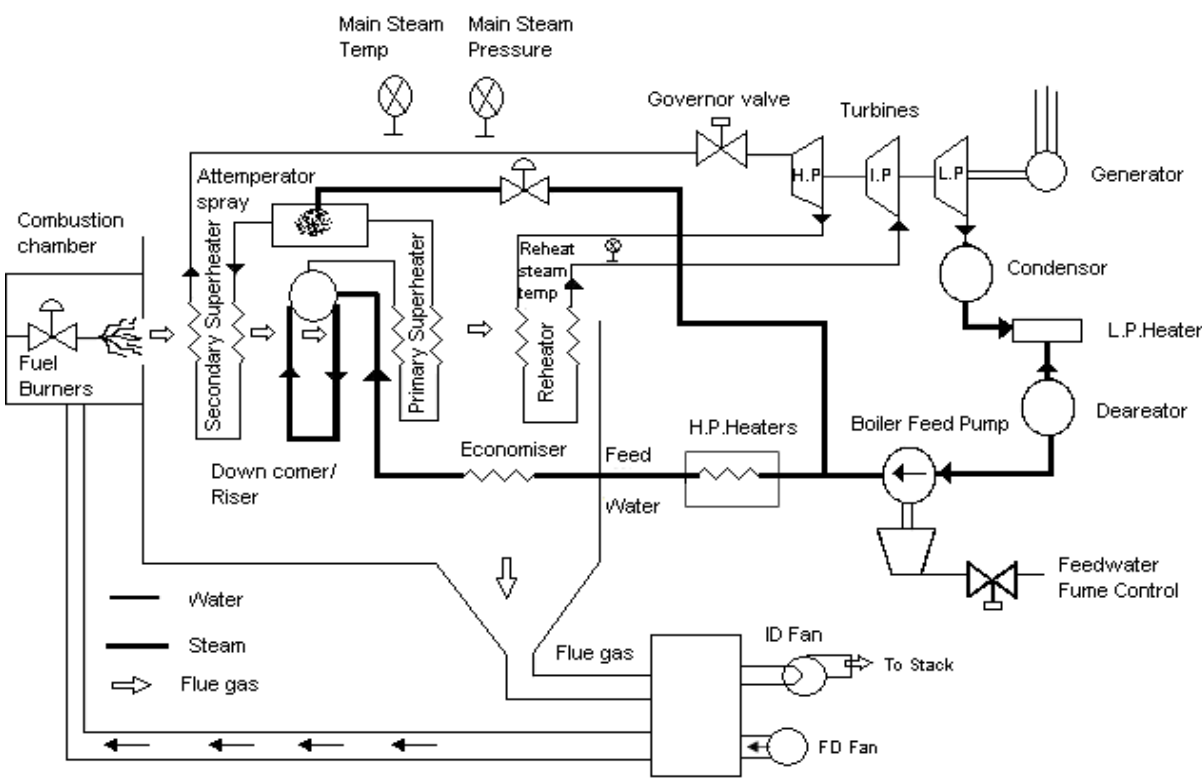

Figure 2. Schematic Diagram of the Power Plant

\section{FUZZY LOGIC GENERALIZED EMBEDDED SYSTEM FOR SUPER HEATER TEMPERATURE CONTROL}

Fuzzy logic operators provide a formal method of manipulating variables that are linguistic. It is a very productive procedure to use fuzzy logic as just another programming paradigm. Fuzzy logic critics are correct in stating that they can do with conventional code everything that fuzzy logic can do.

At some point all of us will say that it is not hot and at some point we will agree that it is hot. The difference between the conditions of beinghot and being not hotmight indicate a temperature that is, to some extent exist in the range between those both conditions.

We can describe temperature in a non-graphical way with declarations that are used in fuzzy logic programming. These declarations describe both the crisp variable Temperature as an unsigned int and a linguistic member HOT as a trapezoid with specific parameters.

To program the linguistic variable HOT to a software program that runs an embedded controller, we need to translate this graphical representation into meaningful code language. The $C$ code fragment gives the proper functionality to work out the process. The function Temperature HOT returns to a degree of membership, scaled between zero and 255, indicating the degree to which a given temperature could be HOT. This kind of simple calculationsare the first tool required for calculations of fuzzy logic operations.

Complex power plant is often controlled manually by experienced operators based on their knowledge of the plant, when the range of the load change is large. As fuzzy logic is capable of incorporating human experiences via the fuzzy rules, online self-organizing fuzzy logic controllers have been proposed for controlling boiler-turbine systems. In addition to direct control applications, fuzzy logics have also been used in designing specifications. Fuzzy logic not only has the ability to approximate nonlinear functions with arbitrary accuracy, they can also be trained from experimental data.

Thus it is made possible through embedded programming. The programmer makes this concept valued through implication of microcontroller circuit and various interfacing methods.

The results obtained from the experimental implementation of the fuzzy generalized controller is given below in Table 1. 
Table 1. Experimental Observations

\begin{tabular}{|c|c|c|}
\hline & PID CONTROLLERS & FIZZY LOGIC CONTROLLERS \\
\hline Peak time(tp) & 0.705 & 052 \\
\hline Rise time(tr) & 0.521 & 0.32 \\
\hline Settling time(ts) & 2.45 & 1.98 \\
\hline Maximum overshoot(Mp) & $32 \%$ & $25.4 \%$ \\
\hline Steady state error(ess) & 1.72 & 1.12 \\
\hline
\end{tabular}

\section{CONCLUSION}

The modeling and control of a 200 MW power plant using the embedded fuzzy approach is discussed in this paper. The embedded fuzzy based boiler control consists of models, and the output of the network is the interpolation of the models using memberships. The proposed embedded fuzzy based boiler controller is similarly constructed. The proposed approach has been successfully applied to model the boiler of a 200 MW power plant, from which the fuzzy based controller is designed. The embedded fuzzy based boiler control is applied first to the simulated power plant before applying it to the actual power plant. Much better performance is obtained from this embedded fuzzy based controller than from the traditional cascade PI controller in controlling the actual power plant under large load changes. Comparison with the cascade PI controller and the linear Generalized Predictive Control is also made on the simulated power plant.

\section{FUTURE SCOPE}

It has been discussed in the paper about the performance of FLC and traditional processes. Each have their own advantages and disadvantages in their own perspective. Further for the future perspective we can use Model Predictive Controller for the unstable process, a pure fuzzy controller structure will only be appropriate for a limited class of systems, since additional filtering action is introduced, thus it will first be of interest to determine sufficient conditions for the MPC controller to include the advantages of the fuzzy controller.

\section{REFERENCES}

The main references are international journals and proceedings. All references should be to the most pertinent and up-todate sources. References are written in Vancouver style. Please use a consistent format for references - see examples below $(9 \mathrm{pt})$ :

[1] Takagi and M.Sugeno, "Fuzzy identification of systems and its applications to modeling and control", IEEE Trans. Syst., Man, Cybern., vol. SMC - 15, no. 1, pp. 116 - 132, Jan./Feb. 1985.

[2] Zhen Xiang, Jinfang Zhang, "Boiler steam temperature control based on linear active disturbance rejection control", IEEE Explore,Control and Decision Conference (CCDC), pp. 1893 - 1897, 23-25 May 2011.

[3] Ankith Rajashekar Mullangi, Sanjay A Menon, Lakshmishree S S, "Temperature control of boiler - improving efficiency

and lifetime"http://www.academia.edu/5476127/BOILER_STEAM_TEMPERATURE_CONTROL_acs_paper

[4] Rahul Malhotra and Rajinder Sodhi, "Boiler Flow Control Using PID and Fuzzy Logic Controller", IJCSET, July 2011, Vol 1, Issue 6,315-319.

[5] Namrata Dey, Ria Mandal, M Monica Subashini, "Design and Implementation of a Water Level Controller using Fuzzy Logic", International Journal of Engineering and Technology (IJET), Vol 5, Issue 3, 2277-2285, Jun-Jul 2013.

[6] T. Karuppiah, V. Sivasankaran, Dr. Azha. Periasamy, Dr. S. Muruganand, "Embedded System Based Industrial Power Plant Boiler Automation Using GSM Technology", International Journal of Advanced Research in Computer and Communication Engineering, Vol. 2, Issue 8, 3321-3325,August 2013.

[7] Om PrakashVerma, GauravManik, "Comparative Analysis of Boiler Drumlevel Control Using Advanced Classical Approaches", International Journal of Engineering Science and Innovative Technology (IJESIT) Volume 2, Issue 5, 125-136, September 2013.

[8] Ravindra Kumar P, Ramchandra Raju V and Ravi Kumar N, "Effect of Parameters in Once-Through Boiler for Controlling Reheat Steam Temperature in Supercritical Power Plants", Research Journal of Engineering Sciences, Vol. 2, Issue 1, 27-34, January 2013. 